\title{
CATEGORIZAÇÃO DA INFRAESTRUTURA VERDE DO MUNICÍPIO DE SOROCABA (SP) PARA CRIAÇÃO DE UM SISTEMA MUNICIPAL INTEGRANDO ESPAÇOS LIVRES E ÁREAS PROTEGIDAS \\ CATEGORIZATION OF GREEN INFRASTRUCTURE IN THE CITY OF SOROCABA (SP) TO CREATE A MUNICIPAL SYSTEM INTEGRATING OPEN SPACES AND PROTECTED AREAS
}

\section{Maurício Tavares da Mota}

Doutorando em Ciências Ambientais pelo Instituto de Ciência e Tecnologia da Universidade Estadual Paulista "Júlio de Mesquita Filho" (UNESP) Campus de Sorocaba, por meio do Programa de Pós-Graduação em Ciências Ambientais (PPGCA). Mestre em Sustentabilidade na Gestão Ambiental pela Universidade Federal de São Carlos (UFSCar)-Sorocaba (SP), Brasil.

\section{Eliana Cardoso-Leite}

Mestre e doutora em Biologia Vegetal pela Universidade Estadual de Campinas (UNICAMP). Docente do Departamento de Ciências Ambientais (DCA) e do Programa de Pós-Graduação em Sustentabilidade na Gestão Ambiental (PPGSGA), do Centro de Ciências e Tecnologias para a Sustentabilidade (CCTS), da UFSCar - Sorocaba (SP), Brasil.

\section{Fernanda Sola}

Doutora em Ciência Ambiental pelo Instituto de Eletrotécnica e Energia do Programa de PósGraduação em Ciência Ambiental (PROCAM) da Universidade de São Paulo (USP). Pesquisadora da USP. Docente do Programa de Mestrado em Sustentabilidade e Gestão Ambiental da UFSCar - Campus Sorocaba - Sorocaba (SP), Brasil.

\section{Kaline de Mello}

Doutoranda em Engenharia de Biossistemas pela Escola Superior de Agricultura Luiz de Queiroz (ESALQ) da USP - Piracicaba (SP), Brasil.

\section{Endereço para correspondência:}

Maurício Tavares da Mota Instituto de Ciência e Tecnologia da Universidade Estadual Paulista "Júlio de Mesquita Filho" (UNESP) - Campus de Sorocaba - 18087-180 - Sorocaba (SP), Brasil-E-mail: mauricio.mota@ posgrad.sorocaba.unesp.br

\section{RESUMO}

As áreas protegidas e os espaços livres no ambiente urbano podem proporcionar diversos serviços ecossistêmicos que contribuem para a melhoria da qualidade de vida. Entretanto, existe uma confusão de terminologia dessas áreas e a gestão delas muitas vezes não é feita de forma integrada. $O$ presente trabalho propõe uma categorização dos elementos naturais no município de Sorocaba (SP) para a criação de um sistema municipal integrando espaços livres e áreas protegidas, com base em suas características físicas, bióticas e suas funções sociais. A metodologia de investigação foi dividida em três etapas: a primeira, revisão bibliográfica do conceito de "parque" utilizado no Brasil e no mundo; a segunda, análise documental e espacial dos espaços livres e áreas protegidas no município de Sorocaba; e a terceira, construção de um sistema municipal de espaços livres e áreas protegidas. A classificação final propõe a divisão dos espaços em categorias, entre elas: Unidades de Conservação, dividida em proteção integral (uso indireto) e uso sustentável (uso direto), Áreas de Interesse Ambiental e Espaços Livres de Uso Público de Interesse Social. Foram ainda traçadas metas de expansão dessas áreas com base em recomendações de órgãos ambientais e nas metas mundiais da Convenção da Diversidade Biológica.

Palavras-chave: gestão municipal; parques urbanos; unidades de conservação.

\section{ABSTRACT}

Protected and open green areas can provide many ecosystem services in the urban environment that contribute to the improvement of the quality of life. However, there is a confusion of terminology between these areas, and their management is often not performed integratedly. This research proposes a categorization of natural elements in the city of Sorocaba, state of São Paulo, Brazil, to create a municipal system integrating open green spaces and protected areas, based on physical and biotic characteristics and social functions of these spaces. The methodology was divided into three steps: first, literature review of the concept of "park" which is used in Brazil and in the world; second, documentary and spatial analysis of open spaces and parks in Sorocaba; third, construction of a municipal system of open spaces and protected areas. The final classification proposes to divide the spaces into categories including: Protected Areas, subdivided into full protection areas (indirect use) and sustainable use (direct use), Environmental Interest Areas and Open Spaces for Public Use and Social Interest. We also proposed goals for the expansion of these areas based on the recommendations of environmental agencies and the global biodiversity targets of the Convention on Biological Diversity.

Keywords: municipal management; urban parks; protected areas. 


\section{INTRODUÇÃO}

A incorporação de elementos naturais ao ambiente urbano é de extrema importância para a melhoria dos serviços ambientais e consequente qualidade de vida das pessoas. Segundo Boada e Sanchez (2012), o futuro de qualquer planejamento sustentável depende da maneira em que se configura e funciona a cidade - em especial no caso da América Latina, onde mais de $80 \%$ da população vive em ambientes urbanos, com estimativa de atingir 90\% em 2050 (PAUCHARD \& BARBOSA, 2013).

Os elementos naturais no ambiente urbano desempenham vários serviços ambientais, sociais e ecológicos, entre os quais: absorção e filtração de poluentes, regulação do microclima, redução de ruído, abrigo para fauna e flora. Ademais, proporcionam paisagem mais agradável esteticamente e oportunidades de recreação, esporte e pesquisa (KABISH \& HAASE, 2013; SCHEWENIUS; MCPHEARSON; ELMQVIST, 2014; HANSMANN et al., 2016). Além disso, os elementos naturais controlam o escoamento pluvial, contribuindo de forma significativa para redução de enchentes (LIU; CHEN; PENG, 2014); proporcionam conforto térmico, que se traduz em bem-estar psicológico (BROWN et al., 2015; KLEMM et al., 2015); assim como oferecem saúde mental à população (DE OLIVEIRA et al., 2013; ALCOCK et al., 2014). Tais serviços traduzem-se em melhoria direta da qualidade de vida e da saúde pública em geral (ERNSTSON, 2013; WOLCH; BYRNE; NEWELL, 2014; DE LIMA SOUSA et al., 2015), sem mencionar os essenciais serviços prestados para dispersão de sementes, controle de pragas e polinização, inseridos em interações complexas nos sistemas sociais-ecológicos urbanos (ANDERSSON et al., 2014).

Muitos são os benefícios da criação de áreas protegidas no ambiente urbano, entretanto, seu estabelecimento pode ser dificultado devido a conflitos de interesse entre a expansão imobiliária e o déficit de áreas verdes com tamanho suficiente para instituição de áreas protegidas (MANEA et al., 2016).

A influência da infraestrutura verde urbana, seus efeitos sobre o conforto humano e sobre a conservação da biodiversidade bem como suas consequências econômicas ainda não estão claras e compreendidas. É possível que essa ausência de compreensão possa ocasionar valoração desses espaços aquém de sua real importância (WANG et al., 2014).

Como consequência, sua gestão, organização e planejamento sempre ficaram relegados ao segundo plano - fato que se confirma ao observar a confusão existente na terminologia desses espaços dotados de vegetação natural total ou parcialmente preservada no ambiente urbano (LIMA et al., 1994). Vários são os termos empregados com o mesmo propósito de designar os espaços livres com vegetação intraurbana. Bargos e Matias (2011) apontam que a vegetação urbana recebe diferentes nomenclaturas, as quais são utilizadas indistintamente como sinônimos do termo para áreas verdes quando, na realidade, em muitos casos não o são.

Os primeiros indícios de reconhecimento da importância desses espaços surgiram no século XVI, com a criação de áreas protegidas intituladas "parques", as quais se expandiram na Europa. Esses espaços passaram a ser valorizados, não só pela importância estética, mas também em função do potencial de promover o equilíbrio ambiental e a melhoria na qualidade de vida em ambientes urbanos (SEGAWA, 2010; HAQ, 2011). Entretanto, segundo Magnoli (2006), foi no século XVIII, também na Europa, que a concepção de utilidade desses espaços motivou a transformação dos parques privados de uso restrito para uso público (OLIVEIRA, 2008).

Desde então, a evolução conceitual dos parques públicos apresentou tendência para formação de parques contínuos e/ou interligados, com a valorização de meios para articulação de diferentes tipologias de espaços verdes urbanos (OLIVEIRA, 2008) que recriam a natureza no interior das cidades como forma de impedir a expansão contínua das edificações, por meio de diretrizes mais específicas que normatizam o uso e a ocupação do solo. Segundo Haase, Frantzeskaki e Elmqvist (2014) e Wu (2014), no século XX surge a ecologia urbana como um subcampo da ecologia, em resposta a uma crescente consciência do impacto humano decorrente da urbanização sobre o meio ambiente natural.

No Brasil, a primeira Unidade de Conservação (UC) data de 1937 e foi inspirada na criação do primeiro Parque Nacional no mundo, em 1872, o Yellostone National Park, nos Estados Unidos. Após algumas décadas de debates sobre um sistema que integrasse todas as categorias de UCs brasileiras, foi publicada, em 2000, a Lei Federal $n^{\circ} 9.985$ (BRASIL, 2000), que trata do Sistema Nacional de Unidades de Conservação (SNUC). O SNUC define dois grupos de UCs: o grupo de proteção integral e o grupo de uso sustentável - o primeiro 
com cinco e o segundo com sete categorias distintas. O próprio SNUC (Artigo $7^{\circ}$ ao $21^{\circ}$ ) deixou aberta a possibilidade dos estados e municípios, quando necessário, para atender suas peculiaridades regionais ou locais, criarem categorias específicas, não previstas na Lei Federal, desde que essas possuíssem objetivos próprios e clara distinção das categorias federais já existentes.

Dessa forma, a grande maioria dos estados da federação optaram por seguir o SNUC (BRASIL, 2000) dentro de seus territórios. No entanto, alguns deles, como Rondônia, Tocantins, Amazonas, Mato Grosso e Maranhão, criaram seus sistemas estaduais (GOVERNO DO ESTADO DE RONDÔNIA, 2002; GOVERNO DO ESTADO DO TOCANTIS, 2005; ESTADO DO AMAZONAS, 2007; GOVERNO DO ESTADO DO MATO GROSSO, 2011; GOVERNO DO ESTADO DO MARANHÃO, 2011), prevendo algumas novas categorias como, por exemplo, Estrada Parque, no Mato Grosso, Amazonas e Tocantins, Rio Cênico no Amazonas e Tocantins, e Reserva Particular do Patrimônio Natural (RPPN) de proteção integral no Amazonas. Alguns estados também suprimiram categorias, como Tocantins, que suprimiu a Reserva Biológica, e Rondônia, que suprimiu a Reserva de Desenvolvimento Sustentável. O estado de São Paulo, como a grande maioria, segue o SNUC, somente adaptando a terminologia para o nível adequado (exemplo: o termo Parque Nacional foi alterado para Parque Estadual).

A problemática no nível local (ou municipal) é maior devido à confusão nomenclatural entre áreas protegidas, cujo objetivo maior é a conservação da natureza, com Espaços Livres de Uso Público. As áreas protegidas, além de conterem amostras significativas dos ecossistemas que pretendem conservar, devem ser criadas pelo órgão ambiental competente, ter gestor devidamente nomeado e um Plano de Manejo elaborado no máximo cinco anos após sua criação (BRASIL, 2000). Já os Espaços Livres de Uso Público podem ou não ser recobertos por vegetação nativa e dispensam as obrigatoriedades descritas para as áreas protegidas. Portanto, um Parque Natural Municipal é uma UC prevista no SNUC (BRASIL,

\section{Objetivos}

Este trabalho teve como objetivos:

- Documentar e classificar os espaços livres (recobertos ou não por elementos naturais) existentes no município de Sorocaba;
2000) e uma área simplesmente denominada "parque" confunde gestores e usuários no que se refere às suas características, objetivos e serviços prestados.

Alguns municípios brasileiros optaram por criar seus sistemas municipais, como foi o caso dos municípios de João Pessoa (PB) (JOÃO PESSOA, 2011), Porto Alegre (RS) (PORTO ALEGRE, 2011) e Belo Horizonte (MG) (BELO HORIZONTE, 2015). Embora o Instituto Chico Mendes de Conservação da Biodiversidade (ICMBIO) (BRASIL, 2010) tenha elaborado o Roteiro para Criação de Unidades de Conservação Municipais, esse somente orienta os municípios, sem discutir a possibilidade de categorias diferentes nos mesmos ou a integração entre áreas protegidas e espaços livres públicos.

Em Porto Alegre, o Sistema Municipal apenas adapta as categorias federais para o nível municipal adequando as nomenclaturas e suprimindo as categorias Floresta Nacional e Reserva Extrativista. Em Belo Horizonte, o sistema recém-criado apenas registra seus princípios e objetivos, deixando a criação das categorias e adequação das áreas já existentes para regulamentação específica. Dos municípios já mencionados, apenas João Pessoa faz uma tentativa de integrar as áreas protegidas, denominadas de UCs com áreas não protegidas, denominadas de Parques Municipais (JOÃO PESSOA, 2011). No entanto, não foi utilizado nenhum critério científico baseado em atributos do meio natural ou físico para separação das áreas nesses dois grupos.

No município de Sorocaba (SP), autores como Mello et al. (2016) estudaram a distribuição e localização de fragmentos de vegetação nativa existentes. Mota, Cardoso-Leite e Sola (2014), utilizando parâmetros como tamanho e qualidade da vegetação, além de outros atributos físicos, propuseram uma distinção entre áreas com potencial para serem UCs e áreas sem esse potencial. No entanto, em Sorocaba, não existem registros de estudos em que áreas protegidas e espaços livres públicos foram analisados de forma conjunta para a proposição de um sistema municipal que possa integrá-los.

- Propor categorias de áreas protegidas e espaços livres para os mesmos;

- Elaborar uma proposta de sistema municipal para áreas protegidas e espaços livres. 


\section{MATERIAL E MÉTODOS}

\section{Caracterização da Área}

O município de Sorocaba localiza-se no sudoeste do estado de São Paulo, entre as coordenadas UTM: 236243 - 265122 m E, 7388590 - 7415800 m S (Figura 1). Segundo dados oficiais do IBGE (2015), o município possui população estimada de 644.919 habitantes, distribuídos em uma área de $448,989 \mathrm{~km}^{2}$. Macedo et al. (2008) destacam a alta densidade populacional nas áreas urbanas consolidadas de Sorocaba e chamam a atenção para a prática da utilização de Áreas

\section{Metodologia}

A elaboração do estudo foi dividida em quatro etapas. A primeira etapa tratou da construção de um referencial teórico sobre as categorias de espaços livres e o conceito de "parques"; a segunda tratou da análise documental e espacial das áreas intituladas "parques" em Soroca-

\section{Etapa 1: Referencial Teórico}

Essa etapa consistiu na construção de um referencial teórico a partir de levantamento bibliográfico sobre os conceitos, de diversos autores em várias localidades do mundo, de espaços livres, áreas verdes, parques, áreas protegidas e/ou UCs. Para a realização desta pesquisa, foram utilizados artigos científicos, teses, revistas, livros, legislações e publicações disponíveis na internet e bibliotecas públicas. Para a busca na de Preservação Permanente (APP) como espaços para instituição de parques.

A região está na transição entre a Mata Atlântica e o cerrado, com cobertura florestal original de floresta estacional semidecídua (IBGE, 2015). Mello et al. (2014) enfatizam o alto grau de fragmentação da vegetação natural no município, com a existência de 2.537 fragmentos de vegetação remanescente, correspondentes a $16,68 \%$ do território. Dos fragmentos identificados pelos autores, 62\% são menores que 1 ha.

ba; a terceira foi a elaboração de um sistema integrado para áreas livres e áreas protegidas para o município; e a quarta etapa consistiu na validação do modelo por meio de consulta pública a gestores, instituições e órgãos com ação direta ou indireta na gestão desses espaços.

internet, utilizaram-se as plataformas de busca Scielo, Periódicos Capes, Google Acadêmico e Web of Science com as seguintes palavras-chave: áreas verdes, espaços livres, áreas protegidas, UCs, parque, sistema municipal de áreas protegidas e sistema municipal de áreas verdes. Essa etapa foi fundamental para subsidiar as etapas seguintes.

\section{Etapa 2: Análise Documental e Espacial dos Espaços Livres de Sorocaba}

Essa fase consistiu em análise espacial em um Sistema de Informações Geográficas (SIG) e levantamento documental de dados relacionados aos espaços livres públicos instituídos como "parques" no município de Sorocaba. Para tanto, foi utilizado o banco de dados da Prefeitura Municipal de Sorocaba.

Para cada uma das áreas, levantou-se o instrumento legal de criação, o qual permitiu avaliar a localização, a identificação, a dimensão e a função original desses espaços. A análise espacial teve como base 66 fotografias aéreas georreferenciadas em escala 1:20.000, com resolução espacial de 0,4 metros, do ano de 2006, que compõem todo o território do município. Com base nas imagens e nas informações estabelecidas na legislação, foram mapeados os limites das áreas públicas bem como o uso e a cobertura do solo com uso do programa ArcGIS 9.0. Com base na rede hidrográfica obtida pela vetorização de cartas topográficas do IGC (escala 1:10.000), foram mapeadas as Áreas de Preservação Permanente (APP). Esses mapas foram utilizados para o cálculo do tamanho da área e a porcentagem de cobertura vegetal.

Foram realizadas também visitas técnicas a todas as áreas públicas e, para cada uma, foi preenchida uma ficha de campo com as seguintes observações: características físicas (presença de recursos hídricos, erosão, 


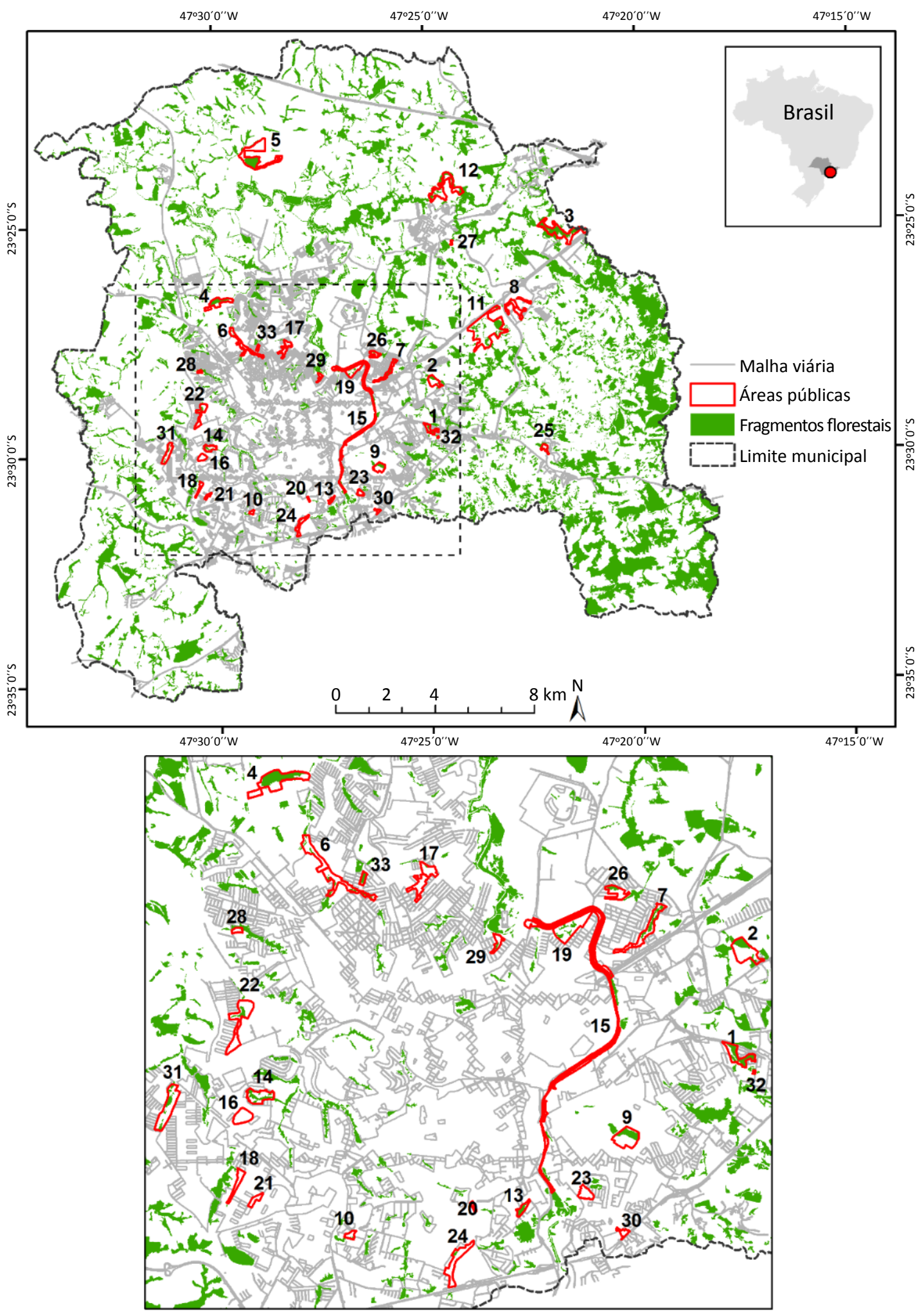

Fonte: Modificado de Mello et al. (2014).

Figura 1 - Município de Sorocaba evidenciando a malha viária e as áreas livres públicas. A descrição de cada área numerada na figura corresponde à descrição existente na Tabela 3. 
assoreamento, impermeabilização do solo e características do entorno), bióticas (identificação do estágio sucessional da vegetação), registro da presença de estruturas e equipamentos de uso público, além de conferência de atributos identificados nas imagens aéreas.
Essa análise permitiu discutir o cenário atual dos Espaços Livres de Uso Público e das áreas protegidas (UC) e sua representatividade em relação aos remanescentes florestais de Sorocaba, identificados por Mello et al. (2014).

\section{Etapa 3: Construção do Sistema Municipal Integrado de Áreas Livres e Áreas Protegidas}

A partir das etapas 1 e 2, foi construído um sistema de classificação dos espaços públicos de Sorocaba, segundo os seguintes critérios: tamanho da área pública, percentual de cobertura florestal nativa da área, função social e função ecológica desses espaços no contexto municipal e análise da qualidade ambiental dessas áreas (MOTA; CARDOSO-LEITE; SOLA, 2014). Os parâmetros para cada critério (Tabela 1) foram definidos com base no SNUC, no levantamento dos remanescentes florestais abordados por Mello et al. (2014) e na literatura adotada na Etapa 1, com destaque para Bastén (2005), Leiria (2012) (Tabela 2) e no trabalho de Mota, Cardoso-Leite e Sola (2014).

Foram considerados UCs os espaços instituídos assim de acordo com o SNUC (BRASIL, 2000). Os critérios mínimos considerados para classificar uma área como UC foram: tamanho mínimo e presença de cobertura florestal nativa (Tabela 1). Além disso, essas áreas foram divididas em UC de Proteção Integral, cujo foco principal é a preservação da natureza e admitem apenas usos indiretos dos recursos naturais, e em UC de Uso Sustentável, que objetivam compatibilizar a conservação da natureza e o uso sustentável dos recursos naturais (Brasil, 2000).

As áreas dotadas de infraestrutura para uso público direto com presença de alguma vegetação nativa foram identificadas como Áreas de Transição (AT). Os parâmetros utilizados foram tamanho total da área e sua porcentagem de vegetação nativa (Tabela 1), além da presença de estruturas para uso público direto, como pistas de caminhada, quiosques, iluminação, banheiros, bancos, playground, entre outras estruturas que potencializam o uso desses espaços para lazer, recreação e convívio social. Para definição dos tamanhos mínimos, foi utilizado principalmente o trabalho de Liira, Lohmus e Tuisk (2012).

Tabela 1 - Tamanho e percentuais mínimos de cobertura florestal utilizados para identificação dos espaços.

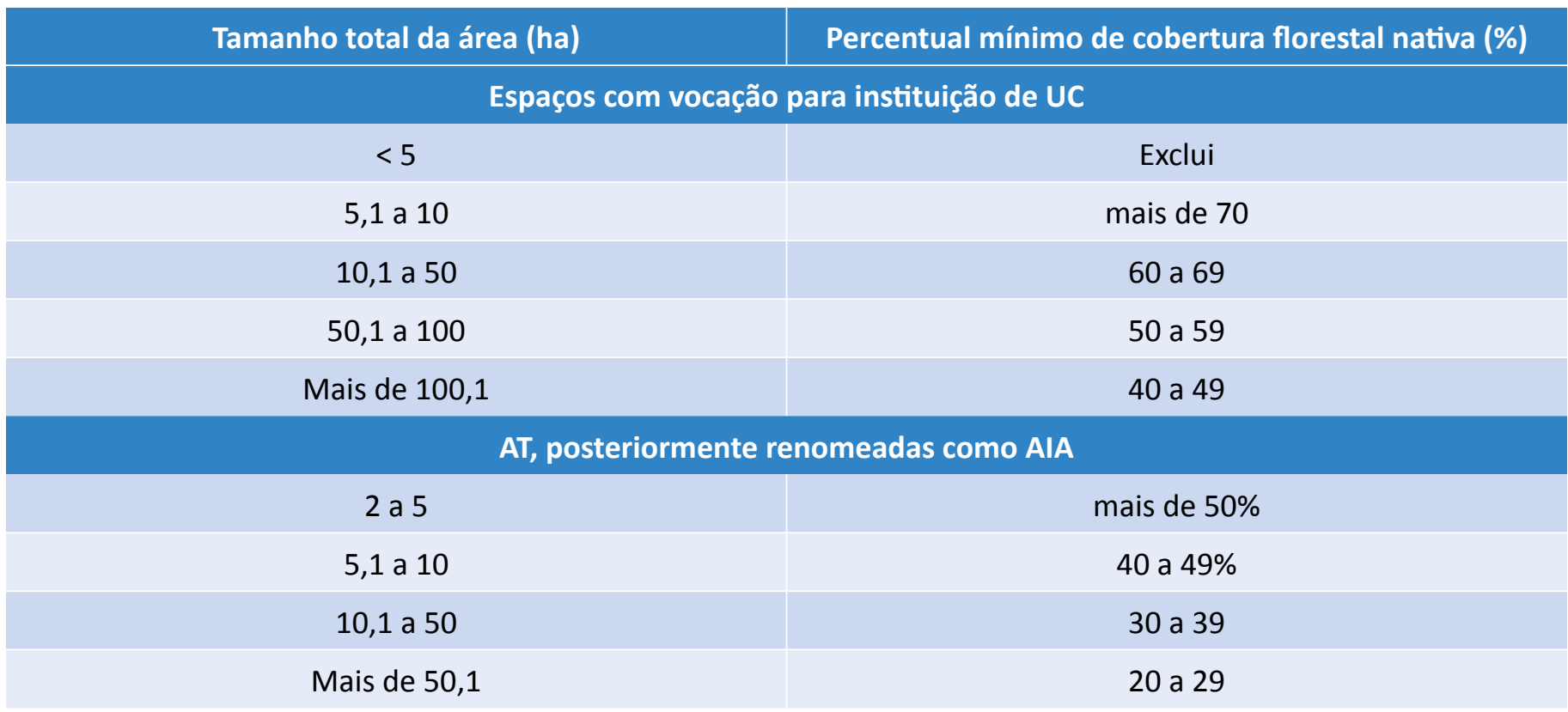

UC: Unidade de Conservação; AT: Área de Transição; AIA: Área de Interesse Ambiental. 
Tabela 2 - Referencial teórico sobre o conceito de "parque" e sua relação com área, característica e função.

\begin{tabular}{|c|c|c|c|}
\hline Autor/ Local & Denominação & Área (ha) & Característica principal \\
\hline \multirow{3}{*}{$\begin{array}{l}\text { Kliass (1993) / } \\
\text { São Paulo -BR }\end{array}$} & Pq. Vizinhança & $10-28$ & Fácil acesso (raio 500 m) para recreação diária. \\
\hline & Pq. De bairro & $48-80$ & Raio de atendimento de $1 \mathrm{~km}$. \\
\hline & Pq. Setoriais & $>200$ & Raio de atendimento de $5 \mathrm{~km}$, alguma cobertura vegetal. \\
\hline \multirow{2}{*}{$\begin{array}{l}\text { SNUC } \\
\text { (BRASIL, 2000) }\end{array}$} & $\begin{array}{l}\text { Unid. Cons. Prot. } \\
\text { Integral }\end{array}$ & Variável & Áreas naturais, objetivo preservação restrita. \\
\hline & $\begin{array}{l}\text { Unid. Cons. Uso } \\
\text { Sustentável (Ex. ARIE) }\end{array}$ & $\begin{array}{l}\text { Em geral } \\
\text { pequenas }\end{array}$ & $\begin{array}{l}\text { Áreas naturais com alguma } \\
\text { alteração e uso direto de recursos. }\end{array}$ \\
\hline \multirow{4}{*}{$\begin{array}{l}\text { Bellester-Olmos e } \\
\text { Carrasco (2001)/ } \\
\text { Espanha }\end{array}$} & Pq. Periurbano & $\geq 10$ & Proteção de flora, fauna e especial beleza cênica. \\
\hline & Bosques Periurbanos & $\geq 25$ & Flora constituída por árvores, nativas ou mista. \\
\hline & Pq. Centrais & & 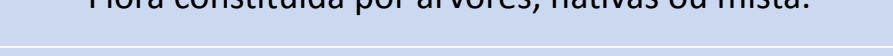 \\
\hline & Pq. Urbano & 10 a 20 & Mínimo 50\% da área com vegetação. \\
\hline \multirow{4}{*}{$\begin{array}{l}\text { Kit Campbell } \\
\text { Associates (2001) } \\
\text { /Escócia }\end{array}$} & Pq. Regional & 400 & Conservação e uso público. \\
\hline & Pq. Metropolitano & 60 & Recreação e desporto. \\
\hline & Pq. Distrital & 20 & Lazer e recreação \\
\hline & Pq. Distrital & Até 8 & Áreas abertas. \\
\hline \multirow{2}{*}{$\begin{array}{l}\text { Diemer, Held e } \\
\text { Hofmeister (2003)/ } \\
\text { Londres - UK }\end{array}$} & Pq. Metropolitano & $>08$ & Áreas abertas com atributos naturais. \\
\hline & Pq. Distrital & Até 08 & Áreas abertas com atributos naturais. \\
\hline \multirow{3}{*}{$\begin{array}{l}\text { Bastén (2005)/ } \\
\text { Chile }\end{array}$} & Pq. Natural & $>100$ & Raio de influência 5 km \\
\hline & Pq. Periurbano & $>10$ & Raio 1 a 2 km \\
\hline & Pq. Urbano & $05-10$ & 1000 a 2000 m \\
\hline $\begin{array}{l}\text { Dover District } \\
\text { Council (2013)/ } \\
\text { Dover - UK }\end{array}$ & Pq. Distrital & $>20$ & Áreas abertas dotadas de atributos naturais. \\
\hline $\begin{array}{l}\text { Brown (2008)/ } \\
\text { Alaska }\end{array}$ & Reserva Natural & $>100$ & Recreação e conservação. \\
\hline $\begin{array}{l}\text { Souza (2010)/ } \\
\text { Curitiba - BR }\end{array}$ & Pq. Urbano & 10 & Próximo a residências. \\
\hline $\begin{array}{l}\text { Flores-Xolocotzi e } \\
\text { González-Guillén } \\
\text { (2010) / México }\end{array}$ & Pq. Urbano & 9,1 & Áreas abertas com características naturais. \\
\hline \multirow{2}{*}{$\begin{array}{l}\text { Byrne e Sipe } \\
\text { (2010) / Austrália }\end{array}$} & Pq. Regional & $25-500+$ & Recreação e desporto com paisagem natural. \\
\hline & Pq. Nacional & $25-1000+$ & Permite recreação, foco principal a conservação. \\
\hline $\begin{array}{l}\text { Falcón (2008)/ } \\
\text { Barcelona - ES }\end{array}$ & Pq. Urbano & $\geq 01$ & Áreas livres. \\
\hline \multirow{3}{*}{$\begin{array}{l}\text { Leiria (2012)/ } \\
\text { Portugal }\end{array}$} & Pq. Suburbano & $\geq 80$ & Áreas abertas com atributos naturais. \\
\hline & Pq. Da Cidade & $\geq 30$ & Áreas abertas com atributos naturais. \\
\hline & Pq. Urbano & $\geq 3$ & Áreas abertas com atributos naturais. \\
\hline $\begin{array}{l}\text { Buccheri-Filho } \\
\text { (2012)/Curitiba BR }\end{array}$ & Parque de Conservação & $\geq 10$ & Áreas públicas para proteção dos recursos naturais. \\
\hline
\end{tabular}

ARIE: Áreas de Relevante Interesse Ecológico. 
Os espaços com potencial predominante para lazer, recreação e paisagismo urbano, sem atributos ecológicos significantes (MOTA; CARDOSO-LEITE; SOLA, 2014), foram identificados como Infraestrutura Verde Urbana (IVU). Esses apresentam predominantemente árvores isoladas, muitas vezes, de espécies exóticas e, quando apresentam vegetação nativa, seu percentual corresponde a menos de $20 \%$ do total da área.

\section{Etapa 4: Validação do Modelo}

Depois de elaborado, o sistema foi submetido à consulta de diversos atores sociais locais envolvidos direta ou indiretamente na gestão desses espaços, dentre eles os secretários de Obras e Urbanismo e de Meio Ambiente de Sorocaba, a comunidade acadêmica e os representantes da sociedade civil. O sistema também foi apresentado em seminários nas universidades públicas do município (UFSCAR e UNESP), nas reuniões públicas do Conselho Municipal de Meio Ambiente (CONDEMA) e à Câmara de
Para análise da suficiência de áreas protegidas no município, foram consideradas as metas estabelecidas pela 11a Meta do Plano Estratégico 2011-2020 acordadas durante a COP 10 da Convenção da Biodiversidade Biológica, conhecidas como Metas de Aichi (CDB, 2012). Essa convenção sugere que um percentual mínimo de $17 \%$ do território do município deve ser constituído por áreas protegidas.

Vereadores. Essas apresentações e discussões ocorreram ao longo dos anos de 2013 e 2014. Opiniões, considerações, críticas e sugestões foram registradas no processo de construção do modelo de classificação dos espaços livres e incorporadas ao sistema final. Como resultante desse processo, os grupos AT e IVU foram renomeados respectivamente para Áreas de Interesse Ambiental (AIA) e Espaços Livres de Uso Público de Interesse Social (ELUPIS), denominados nesses termos ora em diante.

\section{RESULTADOS E DISCUSSÃO}

\section{Etapa 1: Referencial Teórico}

Os diversos autores analisados (Tabela 2) apontam critérios distintos de classificação dos espaços livres, seja com relação à função ou às características, como tamanho e percentual de cobertura vegetal. Porém, há um consenso de que espaços livres são áreas não edificadas, assim como as áreas verdes são uma subcategoria de espaço livre, na qual a vegetação desempenha papel relevante (LIMA et al., 1994).

O termo "parque" por vezes é utilizado para se referir à área verde. Contudo, com definições distintas, variáveis de acordo com a localidade, "parque" denomina desde UCs extensas até pequenas áreas verdes presentes no ambiente urbano.

Muito autores sugerem critérios dos mais variados para propor um sistema de classificação dessas áreas protegidas. A exemplo, Lima et al. (1994) classificam Parque Urbano como área verde com função ecológica, estética e de lazer, mas diferenciam esse espaço de praças e jardins públicos pela dimensão. Para os autores, praças podem ser áreas verdes ou não dotadas de função de lazer, porém com dimensões inferiores aos parques urbanos. De forma semelhante, Kliass (1993) classifica Parque Urbano como uma categoria de área verde pública com dimensões significativas e predominância de elementos naturais, principalmente cobertura vegetal, que contempla, além de função recreativa, normalmente, reconhecidas funções ecológica, estética e de educação (KLIASS, 1993).

Falcón (2008) utiliza o termo Parque Urbano para todo espaço verde urbano com superfície superior a um hectare, que disponha de equipamento básico de uso social. Com relação à vegetação, o autor considera que deva ser contínua à área total e com predomínio de vegetação com porte arbóreo constituindo um fragmento florestal. A Tabela 2 sumariza todas as definições de "parque" utilizadas pelos autores consultados.

Em 2001, foi desenvolvida pela Universidade de Valência uma proposta que permite sistematizar e classificar os diversos espaços verdes urbanos, intitulada "Normas para la classificación de los espacios verdes" (BELLESTER-OLMOS; CARRASCO, 2001). Segundo esse sistema, os Parques Urbanos podem apresentar uma área variável entre 10 e 20 ha e devem servir a mais de um bairro ou a toda a cidade, com funções variadas, 
entre as quais à prática esportiva, ao lazer, às atividades culturais e às funções ecológicas.

No Brasil, alguns exemplos destacam-se, entre os quais Curitiba (PR), que descreve como Parques Urbanos áreas com mais de 10 hectares (SOUZA, 2010). Buccheri-Filho (2012) propõe o termo Parques de Conservação, e indica que devem apresentar extensão mínima de 10 ha.

É possível concluir que, diante das distintas propostas e nomenclaturas, não existe um critério padrão ou consensual entre os autores para diferenciar espaços livres públicos de áreas protegidas e tampouco para diferenciar os espaços livres entre si. Alguns esforços foram feitos com o objetivo de sistematizar e propor modelos de gestão desses espaços, a exemplo do que ocorreu na Europa, com o Projeto GreenKeys. Segundo Smaniotto Costa, Suklje Erjavec e Mathey (2008), esse projeto envolve 20 instituições de 12 cidades, além de 8 instituições de apoio dos países: Bulgária, Alemanha, Grécia, Hungria, Itália, Polônia e Eslovênia. Por meio de uma equipe interdisciplinar, o projeto objetivou desenvolver uma metodologia como ferramenta de apoio para gestão integrada do espaço verde urbano, baseada na troca de experiências por intermédio de uma rede transnacional. Como resultado, surgiram recomendações para prefeituras constituírem políticas públicas urbanas. Esse exemplo ilustra a relevância em construir-se ferramentas de gestão desses espaços.

\section{Etapa 2: Análise Documental e Espacial dos Espaços Livres de Sorocaba}

Foi identificado um total de 33 áreas públicas oficialmente instituídas no município de Sorocaba, em geral intituladas como "parques" (Tabela 3). São áreas verdes destinadas ao lazer, instituídas pela lei, quando da aprovação de projetos de parcelamento do solo (BRASIL, 1979). O percentual de reserva desses espaços era determinado pela Lei Federal n 6.766/1979; entretanto, em emenda ocorrida em 1999, a definição dos percentuais foi transferida ao município. No caso específico de Sorocaba, a lei estabelece que $12 \%$ da gleba parcelada para empreendimentos seja conservada como área livre (SOROCABA, 2014).

Outros parques tiveram sua origem por desapropriações, compensação ambiental pelo impacto de empreendimentos ou doação de áreas à municipalidade. Devido a essas origens, em geral, esses espaços apresentam pequenas dimensões, muitas vezes englobando áreas de preservação permanentes definidas por lei (Lei Federal n 12.651 - BRASIL, 2012), e sua localização é dispersa no território do município (Figura 1). Embora todas elas tenham sido instituídas por instrumentos jurídicos, como leis ou decretos, por ausência de normas específicas no ato de sua criação, constam apenas sua localização, dimensão e denominação, sem pormenorização dos objetivos das mesmas, tampouco um plano de gestão.

Esses espaços apresentam maior potencial urbanístico do que de conservação. Esse fato se deve a intensa urbanização e consequente fragmentação dos remanescentes florestais; ou seja, são poucas as áreas que ainda apresentam potencial para conservação nos moldes de unidades de conservação. Segundo Lin et al. (2016) e Colding (2013), o aumento populacional e o crescimento das cidades são fatores responsáveis pela redução das áreas com potencial para conservação em tamanho e número. Essa situação é evidente no município de Sorocaba: o crescimento urbano e o grande desafio para o bem-estar nas cidades é uma ameaça grave para a biodiversidade (BOTZAT; FISCHER; KOWARIK, 2016).

\section{Etapa 3: Construção do Sistema Municipal Integrado de Áreas Livres e Áreas Protegidas}

Utilizando os critérios mínimos propostos (Tabela 1), associados às conclusões dos autores estudados (Tabela 2), além dos resultados da análise documental e espacial das áreas analisadas por Mota, Cardoso-Leite e Sola (2014), foi elaborado o sistema sintetizado na Figura 2. Sua classificação abrange as seguintes categorias:

- Unidades de Conservação de uso indireto - Com função de conservação e preservação, a área é defi- nida de acordo com suas especificidades no SNUC, que especifica áreas contínuas de fragmentos florestais nativos. Com visita monitorada e controle das formas de uso, o objetivo dessas áreas é a preservação e a conservação de ambientes naturais, processos ecológicos e visitação pública;

- Unidades de Conservação de uso direto - Com função de promover o uso sustentável, trata-se de 
Tabela 3 - Parques instituídos em Sorocaba e seu respectivo instrumento de criação, tamanho da área e cobertura vegetal.

\begin{tabular}{|c|c|c|c|}
\hline & Parque / Instrumento legal de instituição & Área (ha) & $\begin{array}{c}\text { Cobertura } \\
\text { vegetal (\%) }\end{array}$ \\
\hline \multicolumn{4}{|c|}{ Categoria - UC } \\
\hline 1 & Pq. Natural Dr. Braulio Guedes da Silva (Lei $n^{\circ}$ 4.934/95) & 9,38 & 71,55 \\
\hline 2 & Pq. Natural Chico Mendes (Lei $n^{\circ}$ 3.034/89) & 15,17 & 77,73 \\
\hline 3 & Pq. Municipal Mario Covas (Lei $n^{\circ} 6.416 / 01$ ) & 52,67 & 83,14 \\
\hline 4 & Pq. Pedro Paes de Almeida - Horto Municipal (Lei $n^{\circ} 2.815 / 88$ ) & 21,75 & 72,04 \\
\hline 5 & Pq. Natural Municipal Corredores da Biodiversidade (Lei $n^{\circ}$ 10.071/12) & 62,42 & 50,00 \\
\hline \multicolumn{4}{|c|}{ Categoria - AIA } \\
\hline 6 & Pq. Santi Pegoretti Maria Eugênia (Lei n 7.807/06) & 20,56 & 29,69 \\
\hline 7 & Pq. Yves Ota (Lei $n^{\circ} 7.405 / 06$ ) & 12,03 & 45,87 \\
\hline 8 & Pq. Raul de Moura Bittencourt (Lei $n^{\circ} 7.301 / 04$ ) & 20,58 & 31,06 \\
\hline 9 & Pq. Quinzinho de Barros - Zoológico (Lei n 1.087/63) & 13,15 & 32,7 \\
\hline 10 & Pq. João Câncio Pereira - Pq. Água Vermelha (Lei n 3.403/90) & 2,02 & 50,54 \\
\hline 11 & Parque da Cidade (Decretos n. 17.883/09 - 17.902/09) & 120 & 28,14 \\
\hline 12 & Pq. Pirajibu (Decreto n. 16.432/09) & 46,8 & 48,44 \\
\hline 13 & Pq. Da Biquinha & 2,88 & 86,80 \\
\hline 14 & Pq. Ouro Fino & 9,69 & 47,6 \\
\hline \multicolumn{4}{|c|}{ Categoria - ELUPIS } \\
\hline 15 & Pq. Linear - Armando Pannunzio (Lei n 8.521/08 - Decreto n. 19.518/11) & 1074 & 0,5 \\
\hline 16 & Pq. Maestro Nilson Lombardi (Lei $n^{\circ} 8.449 / 08$ ) & 7,31 & 0,00 \\
\hline 17 & Pq. Flávio Trettel - Vila Formosa (Lei nº 8.446/08) & 11,95 & 9,17 \\
\hline 18 & Pq. Natural Antônio Latorre (Lei $n^{\circ} 7.985 / 06$ ) & 4,45 & 19,10 \\
\hline 19 & Pq. Maria Barbosa Silva - (Lei n 7.855/06 - Decreto n. 17.887/09) & 16,39 & 2,98 \\
\hline 20 & Pq. Kasato Maru (Lei $\left.n^{\circ} 7.845 / 06\right)$ & 0,94 & 17,29 \\
\hline 21 & Pq. Natural João Pellegrini (Lei $\left.n^{\circ} 7.665 / 06\right)$ & 2,59 & 10,31 \\
\hline 22 & Pq. Natural da Cachoeira - Dr. Eduardo Alvarenga (Lei nº 7.379/05) & 15,82 & 17,95 \\
\hline 23 & Pq. Dos Espanhóis (Lei nº 8.536/08) & 4,74 & 9,17 \\
\hline 24 & Pq. Carlos Alberto de Souza (Decreto n 14.418/05) & 10,43 & 20,71 \\
\hline 25 & Pq. Brigadeiro Tobias (Decreto $\mathrm{n}^{\circ} 19.372 / 11$ ) & 4,56 & 28,28 \\
\hline 26 & Pq. Jd. Botânico (Decreto n 18.567/10) & 6,51 & 18,43 \\
\hline 27 & Pq. Do Éden (Decreto n 18.468/10) & 0,81 & 7,40 \\
\hline 28 & Pq. Walter Grillo (Lei n 8.506/08 - Decreto n. 18.287/10) & 1,56 & 40,38 \\
\hline 29 & Pq. Antônio Amaro Mendes - Jd. Brasilândia (Lei n 8.440/08 & 3,35 & 22,08 \\
\hline 30 & Pq. Municipal Profa. Margarida L. Camargo (Lei n 7.155/04) & 1,91 & 11 \\
\hline 31 & Pq. Miguel Gregório de Oliveira (Lei $n^{\circ} 6.443 / 01$ ) & 15,25 & 26,69 \\
\hline 32 & Pq. Steven Paul Jobs (Lei $n^{\circ}$ 10.070/12) & 0,28 & 96,42 \\
\hline 33 & Pq. Natural Juracy Antônio Boaro (Lei n 7.940/06) & 1,87 & 71,00 \\
\hline
\end{tabular}

UC: Unidades de Conservação; AIA: Áreas de Interesse Ambiental; ELUPIS: Espaços Livres de Uso Público de Interesse Social. 


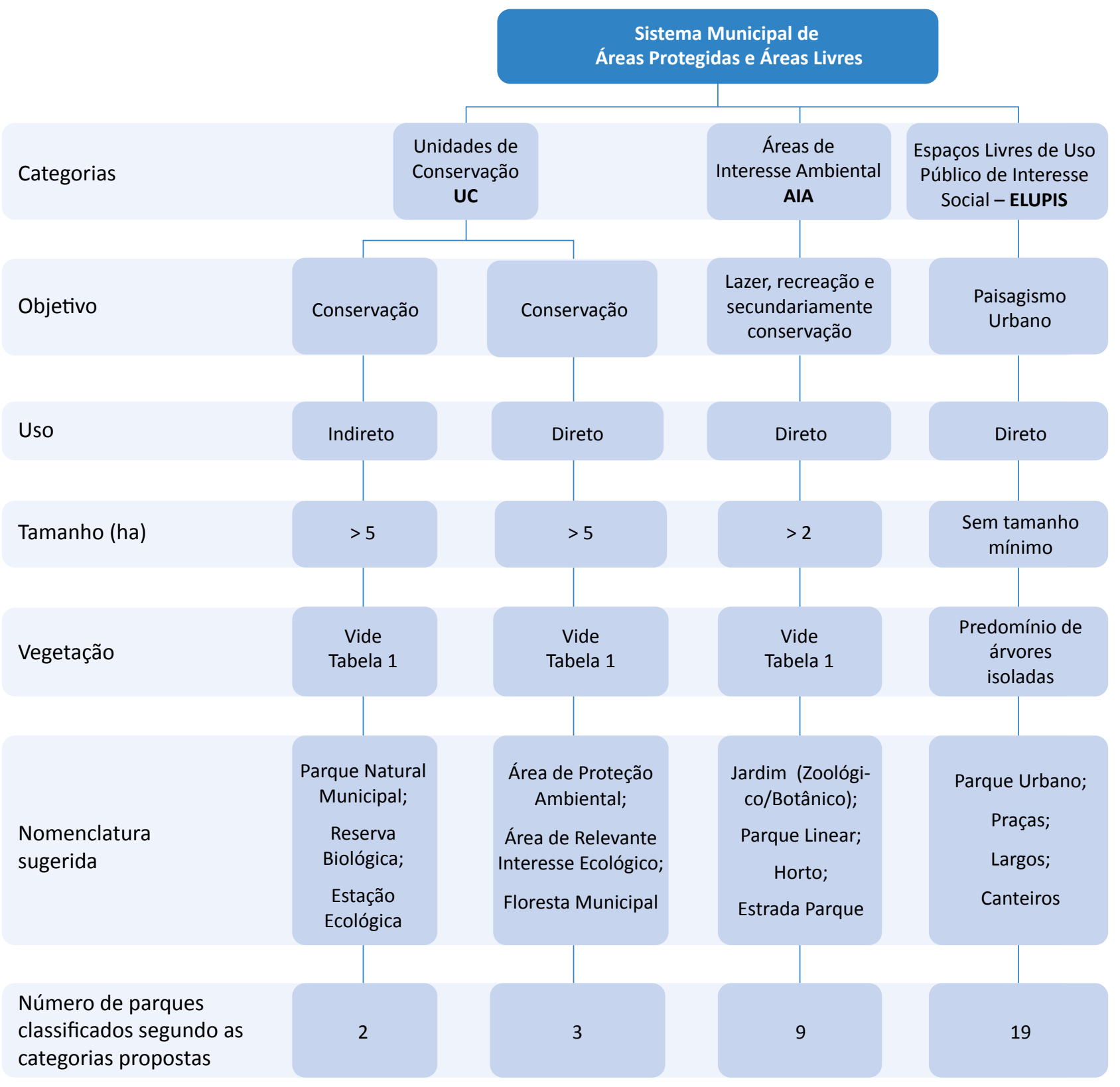

Figura 2 - Sistema integrando áreas livres e áreas protegidas no município de Sorocaba.

espaços com possibilidade de uso direto pela população com fins recreativos, de lazer, educacionais e função contemplativa. Dotados de fragmentos florestais nativos, não há controle no processo de visita. Esses espaços estão inseridos em meio altamente urbanizado;

- Áreas de Interesse Ambiental - Caracterizadas por espaços urbanos com valor ecológico onde há a pre- sença de fragmentos florestais nativos, com percentual de ocupação variável de acordo com o tamanho da área, podendo conter elementos de conservação ex-situ;

- Espaços livres de uso público de interesse social São áreas sem definição de tamanho, com predomínio de árvores isoladas ou vegetação ornamental. Em caso de presença de fragmentos florestais, es- 
ses não atingem os percentuais mínimos das Áreas de Interesse Ambiental. São espaços livres encravados em meio urbanizado, com presença de vegetação ornamental e/ou vegetação arbórea isolada com objetivo paisagístico.

De um total de 33 áreas analisadas, 5 foram identificadas como UC, 9 como AIA e 19 como ELUPIS (Tabela 3). A distribuição em extensão territorial dos espaços livres apresentou predominância na categoria ELUPIS, com $74 \%$ do território das áreas analisadas, $16 \%$ na categoria AIA e apenas $10 \%$ na categoria UC.

As áreas "Corredores da Biodiversidade" e "Mário Covas", devido ao potencial ecológico (MOTA; CARDOSO-LEITE; SOLA, 2014), foram enquadradas na categoria UC de proteção integral. A classificação dessas áreas como Parques Naturais Municipais é importante para que haja a padronização com a nomenclatura oficial do Brasil descrita no SNUC (BRASIL, 2000) e, assim, seguir as diretrizes de gestão estabelecidas pelo SNUC.

As áreas "Chico Mendes", "Horto" e "Braúlio Guedes", por estarem inseridas em meio altamente urbanizado com forte potencial para uso direto, porém com potencial ecológico importante (MOTA; CARDOSO-LEITE; SOLA, 2014), foram classificadas como UC de uso sustentável, podendo ser reclassificadas como Florestas Municipais (FLOMA) ou Áreas de Relevante Interesse Ecológico (ARIE), para enquadrarem-se no SNUC (BRASIL, 2000). Vale ressaltar que essas áreas (Figura 1) estão todas localizadas na porção N e NE do município de Sorocaba, sendo que na porção S e SE existem fragmentos de vegetação nativa com tamanhos relativamente grandes (> 50 ha) (MELLO et al., 2016) que não estão protegidos por lei pois, na sua grande maioria, são áreas de posse particular.

Os espaços identificados como AIA possuem características urbanísticas como estrutura para recreação, lazer e paisagística, e educação ambiental; entretanto, apresentam alguns atributos naturais. Já os espaços identificados como ELUPIS não apresentam atributos naturais significativos. Em geral, são pequenos e/ou possuem a maior parte de sua extensão pavimentada e ocupada por infraestrutura urbana (calçada, equipamentos públicos, ciclovia e pista de caminhada).
Os espaços identificados como AIAs podem mudar para a categoria de UC, se houver a implantação de projetos de restauração, como, por exemplo, no Parque Ouro Fino (área 14, Tabela 3), que possui fragmento florestal remanescente e áreas de plantio de árvores nativas para recomposição florestal. Isso vale também para outras áreas, como sugerido pelo gestor das áreas protegidas da Secretaria Municipal do Meio Ambiente em uma das consultas públicas realizadas, que acredita que as áreas que possuem projetos de recuperação em andamento podem ser incluídas nas categorias mais restritivas. Outro exemplo desse caso é o Pirajibu (área 12 , Tabela 3) que, por não obter mais de $50 \%$ de cobertura nativa, foi classificado como AIA. Nesse caso, essa área é muito importante para a conservação do Rio Pirajibu, pois envolve suas matas ciliares. Sendo assim, programas de restauração ecológica nessa área podem contribuir para a conservação da zona ripária e para a reclassificação da mesma em UC.

Em geral, é comum que haja nas áreas urbanas áreas protegidas vinculadas a faixas de preservação permanente de rios e córregos, dada a necessidade dos cidadãos de aproximarem-se dos cursos d'água. Essas são as razões do surgimento de uma grande quantidade de parques lineares e corredores verdes - fato também comum nas cidades ibéricas (FRANCO et al., 2014).

As áreas identificadas com potencial para criação de UC podem exercer papel fundamental para a manutenção de serviços ambientais e para a biodiversidade do município quando associadas aos corredores de mata ciliar presentes nas APP conservadas do município. Segundo Mello et al. (2014), as APP dotadas de vegetação nativa representam mais da metade dos remanescentes florestais existentes no município, equivalente a 3.799 hectares. Essas áreas somadas às áreas dos parques identificados como UC representariam um total de 3.960 hectares.

Esse diagnóstico permite concluir que, para se atingir as metas propostas pela CDB (2012), que sugere como ideal pelo menos $17 \%$ do território mantido em áreas protegidas, o município de Sorocaba deveria ter 7.653 ha em áreas protegidas legalmente, o que resulta num déficit atual de 3.693 ha. Uma vez que as áreas de APP sem vegetação, excluídas as áreas urbanizadas e consolidadas identificadas por Mello et al. (2014), equivalem a 3.800 hectares, apenas a restauração das APP do 
município seria suficiente para a superação dessa meta internacional, sem a necessidade premente da instituição de novos parques no município. Entretanto, como a restauração ecológica dessas áreas apresenta um custo econômico bastante elevado, mesmo considerando o custo de desapropriações, a criação de novas UC pode ser uma alternativa mais interessante para a gestão municipal, uma vez que o município possui ainda 3.710 ha de vegetação nativa fora da faixa de APP (MELLO et al., 2014).

Essas metas podem parecer ousadas, mas diversos casos pelo mundo demonstram que a expansão das áreas verdes é possível. Como exemplo, Mc Phearson et al. (2013) comprovam que Nova lorque contém mais parques do que qualquer outra cidade dos EUA e tem $21 \%$ do solo coberto por árvores, o que deverá aumentar, segundo os autores, nas próximas décadas. Considerando o alto valor do metro quadrado em Nova lorque, conquistar espaços protegidos é reflexo do reconhecimento de sua importância.

Uma estratégia para a promoção da expansão de áreas protegidas e áreas verdes é a integração com a implantação de corredores ecológicos. Segundo Maes et al. (2015), a conexão de áreas protegidas urbanas por meio de um modelo integrado é essencial para a manutenção da biodiversidade e de serviços fundamentais do ecossistema. Os autores destacam ainda que a IVU das cidades está vinculada à saúde humana por meio dos serviços ecossistêmicos que são prestados por parques urbanos, cinturões verdes periurbanos, ou florestas e áreas semi-naturais que cercam as cidades. Tais benefícios para a saúde estão associados à melhor qualidade do ar, à regulação do microclima por meio dos efeitos de resfriamento de vegetação, à recreação, à saúde psicológica e ao bem-estar mental. Barbati et al. (2013) citam que as áreas protegidas são essenciais para a conservação da biodiversidade e demonstram que, além de áreas com extensões maiores, as pequenas vias (ruas) podem ser elementos importantes para conexão e integração dos espaços verdes, por meio da implantação de projetos de arborização. Nesse contexto, Newell et al. (2013), demonstraram o efeito positivo da arborização de vielas para integração dos espaços verdes em cidades e aumento de seu potencial benéfico. Portanto, é evidente que todas as áreas verdes são essenciais, independentemente de seu tamanho, fun- ção e característica, visto que exercem serviços ecossitêmicos de extrema relevância.

Lafortezza et al. (2013) destacam que, além dos benefícios citados, a existência de áreas protegidas e espaços verdes pode potencializar o envolvimento das pessoas com o ambiente natural e propiciar um aumento na expectativa de vida, além de estimular a prática de atividades físicas e promover ligações culturais, ecológicas e psicológicas com o ambiente. Segundo Daniel et al. (2012), embora reconhecidas, essas relações culturais têm sido menos estudadas entre os diferentes tipos de serviços ecossistêmicos, em parte porque a maioria dos serviços culturais são intangíveis e não materiais.

Além da importância das relações culturais, Andersson et al. (2014) destacam que, apesar das inúmeras conclusões acerca dos benefícios, ainda estamos começando a compreender a importância das áreas verdes urbanas, portanto, temos uma compreensão limitada dos mecanismos por trás da geração de serviços de ecossistemas urbanos.

Kabisch, Qureshi e Haase (2015) corroboram essa ideia ao afirmar que ainda é incompleta a compreensão geral das questões de interação humano-ambiente contemporâneo no espaço verde urbano, e que falta orientação para os planejadores urbanos. No entanto, Baró et al. (2014) destacam que, em pesquisa na cidade de Barcelona, Espanha, cidade em que é significativa a contribuição dos serviços ambientais prestados pelas florestas urbanas na promoção da qualidade de vida, esses serviços raramente são explicitamente considerados nas metas de política ambiental.

Valorar a importância dos espaços protegidos no ambiente urbano é essencial, porém a falta de reconhecimento não é exclusiva ao Brasil. Na Europa, Hansmann et al. (2016) e Lennon (2015) também concluíram como essencial a conquista do reconhecimento por parte de políticos e do público a fim de atingir o sucesso na gestão da infraestrutura verde urbana. Em geral, os benefícios para o bem estar, a qualidade de vida e o ambiente não são bem compreendidos pelo público.

Essa falta de compreensão afeta diretamente a gestão desses espaços, afinal o cumprimento efetivo de tais benefícios depende de uma governança eficaz. Não basta a instituição de um sistema teórico; esse deve ser colocado em prática e aprimorado de acordo 
com as necessidades identificadas. Esse é o principal desafio observado neste estudo e corrobora com as conclusões de Andersson et al. (2014).

Segundo Cardoso et al. (2015), no âmbito urbano, a governança é compreendida como desconcentração do Estado como entidade jurídica soberana nas ações pertinentes à esfera municipal. Envolve a articulação e a coordenação de políticas públicas entre órgãos governamentais e instituições sociais, com mudanças na execução de políticas públicas urbanas até então centradas em entidades municipais para uma gestão compartilhada. Mas, para sua efetivação, é necessária a

\section{Etapa 4: Validação do Modelo}

A categorização das áreas municipais é importante para facilitar sua gestão de forma integrada, a fim de que todas essas áreas façam parte de um único sistema que incorpore tanto a preocupação ambiental como a melhoria da qualidade de vida da população no ambiente urbano.

O resultado desse estudo, constituído por meio de uma minuta de projeto de lei, foi apresentado e submetido a discussões junto ao CONDEMA, a gestores locais, à Câmara Municipal de Sorocaba e à sociedade como um correta compreensão das interações homem-ambiente. O processo de criação e gestão de territórios dedicados à conservação de atributos naturais representa um fenômeno de grande complexidade, pois envolve, além de aspectos associados à conservação de atributos naturais, aspectos socioculturais, políticos e econômicos (SANCHO \& DE DEUS, 2015).

Tal complexidade exige instrumentos eficazes de planejamento e organização, elementos fundamentais para efetivação do paradigma da sustentabilidade urbana (AHERN, 2013; CUMMING et al., 2013; SWAFFIELD, 2013; XIANG, 2013).

todo. As devidas sugestões, considerações e alterações foram acatadas e um texto final foi submetido à Câmara Municipal de Sorocaba para apreciação, com a finalidade de constituir um projeto de lei. A proposta foi aceita por membro do poder legislativo municipal, que converteu a minuta no Projeto de Lei $n^{\circ} 116 / 2014$. O Projeto obteve aprovação e foi sancionado em Lei Municipal (SOROCABA, 2015 - Lei Municipal $n^{\circ} 11.073$ de 31 de março de 2015), que institui o Sistema Municipal de Áreas Protegidas, Parques e Espaços Livres de Uso Público, que seguiu a proposta apresentada nesse estudo.

\section{CONCLUSÃO}

Os espaços livres e áreas protegidas foram classificados e documentados de acordo com seus atributos (tamanho e percentual de vegetação). As características dessas áreas permitiram identificar padrões de tamanho e percentual de vegetação específicos para o município de Sorocaba. Esses referenciais possibilitaram propor sua organização em três categorias: Unidades de Conservação, Áreas de Interesse Ambiental e Espaços Livres de Uso Público de Interesse Social, modelo que incorpora áreas com vocação para conservação, espaços de lazer e recreação e espaços urbanos que podem ser geridos de forma sistêmica com objetivo de atingir interconexões desses espaços. Entre as áreas já instituídas, foi possível concluir que há predomínio de áreas com potencial urbanístico, tanto em número como extensão territorial - reflexo do alto grau de urbanização do município.

O sistema proposto permite construir uma concepção holística dos espaços existentes e possibilita uma gestão que vislumbre a conexão dos mais diversos espaços livres e áreas protegidas, com possibilidade de atingir metas de expansão em consonância com os parâmetros sugeridos para conservação da biodiversidade e promoção da qualidade de vida urbana. O modelo construído nesse trabalho pode ser uma ferramenta importante para orientar a gestão compartilhada dos espaços livres e áreas protegidas, inclusive em outros municípios brasileiros, com necessidade de revisão periódica e participativa. Porém deve ser adaptado à realidade de cada localidade.

Embora os resultados desta pesquisa tenham servido de base para a elaboração e sanção da Lei Municipal $n^{\circ} 11.073$ de 31 de março de 2015, desde sua vigência, o processo de adequação das áreas existentes ao sistema ocorreu de forma tímida, principalmente por escassez de recursos. É essencial que novas pesquisas apontem diretrizes para a evolução do modelo, principalmente com ênfase na integração das categorias, 
por meio da formação de pseudocorredores verdes conectados.

Esse modelo é recomendado por diversos autores na Europa e reconhecido como um desafio a ser atingido. Entretanto, o desafio maior consiste em conquistar o reconhecimento do público e de autoridades responsáveis por sua gestão assim como e conseguir que políticos e o público em geral compreendam a importância dos espaços protegidos no ambiente urbano, fundamental para atingir o sucesso na gestão da infraestrutura verde urbana.

\section{REFERÊNCIAS}

AHERN, J. Urban landscape sustainability and resilience: the promise and challenges of integrating ecology with urban planning and design. Landscape Ecology, v. 28, p. 1203-1212, 2013.

ALCOCK, I.; WHITE, M.P., WHEELER, B.W.; FLEMING, L.E.; DEPLEDGE, M.H. Longitudinal effects on mental health of moving to greener and less green urban areas. Environmental Science \& Technology, v. 48, n. 2, p. 1247-1255, 2014.

ANDERSSON, E.; BARTHEL, S.; BORGSTRÖM, S.; COLDING, J.; ELMQVIST, T.; FOLKE, C.; GREN, Å. Reconnecting cities to the biosphere: Stewardship of green infrastructure and urban ecosystem services. Ambio, v. 43, n. 4, p. 445-453, 2014.

BARBATI, A.; CORONA, P.; SALVATI, L.; GASPARELLA, L. Natural forest expansion into suburban countryside: Gained ground for a green infrastructure? Urban Forestry \& Urban Greening, v. 12, n. 1, p. 36-43, 2013.

BARGOS, D.C. \& MATIAS, L.F. Áreas verdes urbanas: um estudo de revisão e proposta conceitual. REVSBAU, Piracicaba, v. 6, n. 3, p. $172-188,2011$.

BARÓ, F.; CHAPARRO, L.; GÓMEZ-BAGGETHUN, E.; LANGEMEYER, J.; NOWAK, D.J.; TERRADAS, J. Contribution of ecosystem services to air quality and climate change mitigation policies: the case of urban forests in Barcelona, Spain. Ambio, v. 43, n. 4, p. 466-479, 2014.

BASTÉN, V.G. Sobre sistemas, tipologias y estándares de áreas verdes em el planeamiento urbano. Revista Electrônica Diseño Urbano y Paisaje, v. 2, n. 6, 2005.

BELLESTER-OLMOS, J. \& CARRASCO, A.A. Normas para la clasificación de los espacios verdes. Valência: Universidade Politécnica de Valência, 2001. 187p.

BELO HORIZONTE. Lei n. ${ }^{\circ}$ 10.879, de 27 de novembro de 2015. Institui o Sistema Municipal de Áreas Protegidas de Belo Horizonte e dá outras providências. Diário Oficial do Município, Belo Horizonte, 2015.

BOADA, M. \& SANCHEZ, S. Naturaleza y cultura, biodiversidad urbana. In: OMETO, A.R.; PERES, R.B.; SAADEVRA, Y.M.B (Orgs.). Ecoinovação para a melhoria de produtos e serviços: experiências espanholas e brasileiras nos setores industrial, urbano e agrícola. São Carlos. Diagrama, 2012.

BOTZAT, A.; FISCHER, L.K.; KOWARIK, I. Unexploited opportunities in understanding liveable and biodiverse cities. A review on urban biodiversity perception and valuation. Global Environmental Change, v. 39, p. 220-233, 2016.

BRASIL. Lei n. ${ }^{\circ}$ 6.766, de 19 de dezembro de 1979. Dispõe sobre o Parcelamento do Solo Urbano e dá outras Providências. Diário Oficial da República Federativa do Brasil, Brasília, 1979.

BRASIL. Lei n. ${ }^{\circ}$ 12.651, de 25 de maio de 2012. Dispõe sobre a proteção da vegetação nativa. Diário Oficial da União da República Federativa do Brasil, Brasília, v. 149, n. 102, p. 1-8, 28 maio 2012.

BRASIL. Ministério do Meio Ambiente. Roteiro para criação de unidades de conservação municipais. João Carlos Costa Oliveira/José Henrique Cerqueira Barbosa. Brasília: Ministério do Meio Ambiente, 2010. 68p. 
BRASIL. SNUC-Sistema Nacional de Unidades de Conservação. Lei Federal n. ${ }^{\circ} 9.985$ de 18 de julho de 2000. Regulamenta o art. 225, § $1 .^{\circ}$, incisos, I, II, III e VII da Constituição Federal, institui o Sistema Nacional de Unidades da Conservação e dá outras providências. Diário Oficial da União da República Federativa do Brasil, Brasília, 2000.

BROWN, G. A theory of urban park geophaphy. Journal of Leisure Research, v. 40, n. 4, p. 589-607, 2008. Disponível em: <www.landscapemap2.org/publications/JLR_Brown.pdf>. Acesso em: 1. ${ }^{\circ}$ abr. 2015.

BROWN, R.D.; VANOS, J.; KENNY, N.; LENZHOLZER, S. Designing urban parks that ameliorate the effects of climate change. Landscape and Urban Planning, v. 138, p. 118-131, 2015.

BUCCHERI-FILHO, A.T. O planejamento dos parques no município de Curitiba, PR: planejamento sistemático ou planejamento baseado em um modelo oportunista? Caminhos de Geografia, Uberlândia, v. 13, n. 41, p. 206-222, 2012.

BYRNE, J. \& SIPE, N. Green and open space planning for urban consolidation: a review of the literature and best practice. Urban Research Program, n. 11, 2010. Disponível em: <http://www98.griffith.edu.au/dspace/bitstream/ handle/10072/34502/62968_1.pdf?sequence=1>. Acesso em: 1. ${ }^{\circ}$ abr. 2015.

CARDOSO, S.L.C.; VASCONCELLOS SOBRINHO, M.; VASCONCELLOS, A.M.A. Gestão ambiental de parques urbanos: o caso do Parque Ecológico do Município de Belém Gunnar Vingren. urbe, v. 7, n. 1, p. 74-90, 2015.

CDB - CONVENTION ON BIOLOGICAL DIVERSITY. Aichi biodiversity targets. 2012. Disponível em: <http://www.cbd.int/ sp/targets>. Acesso em: $1 .^{\circ}$ abr. 2015.

COLDING, J. Local assessment of Stockholm: Revisiting the Stockholm Urban Assessment. In: ELMQVIST, T.; FRAGKIAS, M.; GOODNESS, J.; GÜNERALP, B.; MARCOTULLIO, P.J.; MCDONALD, R.I.; PARNELL, S.; SCHEWENIUS, M., SENDSTAD, M.; SETO, K.C.; WILKINSON, C. (Eds.). Urbanization, biodiversity and ecosystem services: challenges and opportunities. [S.I.]: Springer, 2013. p. 313-335.

CUMMING, G.S.; OLSSON, P.; CHAPIN, F.S., III; HOLLING, C.S. Resilience, experimentation, and scale mismatches in social-ecological landscapes. Landscape Ecology, v. 28, p. 1139-1150, 2013.

DANIEL, T.C.; MUHAR, A.; ARNBERGER, A.; AZNAR, O.; BOYD, J.W.; CHAN, K.M.A. Contributions of cultural services to the ecosystem services agenda. Proceedings of the National Academy of Sciences of the United States of America, $\mathrm{v}$. 109, p. 8812-8819, 2012.

DE LIMA SOUSA, A.; DE SOUZA MEDEIROS, J.; DA SILVA ALBUQUERQUE, D.; HIGUCHI, M.I.G. Parque Verde Urbano como Espaço de Desenvolvimento Psicossocial e Sensibilização Socioambiental. Psico, v. 46, n. 3, p. 301-310, 2015.

DE OLIVEIRA, E.S.; ASPINALL, P.; BRIGGS, A.; CUMMINS, S.; LEYLAND, A.H.; MITCHELL, R.; THOMPSON, C.W. How effective is the Forestry Commission Scotland's woodland improvement programme - 'Woods In and Around Towns' (WIAT) at improving psychological well-being in deprived urban communities? A quasi-experimental study. BMJ Open, v. 3, n. 8, p. 3648, 2013.

DIEMER, M.; HELD, M.H.; HOFMEISTER, S. (Orgs). Urban Wilderness in Central Europe - Rewilding at the Urban Fringe. International Journal of Wilderness, v. 9, n. 3, 2003. Disponível em: <http://www.wilderness.net/library/documents/ IJWDec03_DiemerHeldHofmeister.pdf>. Acesso em: 1. ${ }^{\circ}$ mar. 2015.

DOVER DISTRICT COUNCIL. Parks and Amenity Open Space Strategy. 2013. Disponível em: <http://www.dover.gov. uk/Leisure-Culture-Tourism/Leisure-Facilities/PDF/Parks-and-Amenity-Open-Space-Strategy.pdf>. Acesso em: $1 .^{\circ}$ abr. 2015.

ERNSTSON, H. The social production of ecosystem services: a framework for studying environmental justice and ecological complexity in urbanized landscapes. Landscape and Urban Planning, v. 109, n. 1, p. 7-17, 2013. 
ESTADO DO AMAZONAS. Lei Complementar n. 53, de 5 de junho de 2007. Institui o Sistema Estadual de Unidades de Conservação. Assembleia Legislativa, 2007.

FALCÓN, A. Espacios Verdes para uma ciudad Sostenible. IV Jornada Planificación y Gestión Sostenibe del Paisaje Urbana. 2008. Disponível em: <http://www.dphuesca.es/pub/documentos/documentos_ESPACIOS_VERDES_PARA_ UNA_CIUDAD_SOSTENIBLE_Sr_Antoni_Falcon_Consejero_Delegado_de_Materia_Verda_3217bfb5.pdf $>$. Acesso em: 24 maio 2012.

FLORES-XOLOCOTZI, R.; GONZÁLEZ-GUILLÉN, M.J. Planificación de sistemas de áreas verdes y parques públicos de algunas ciudades del mundo. Revista Mexicana de Ciencias Forestales, v. 1, n. 1, 2010.

FRANCO, M.D.A.R.; CASTAÑER, C.M.; DA CRUZ, R. Infraestrutura verde e resiliência urbana para as mudanças climáticas na Península Ibérica: estudos de caso. Revista LABVERDE, v. 9, p. 128-163, 2014.

GOVERNO DO ESTADO DE RONDÔNIA. Decreto-lei n. 1.144 de 12 de dezembro de 2002. Dispõe sobre o Sistema Estadual de Unidades de Conservação da Natureza de Rondônia - SEUC/RO e dá outras providências. Diário Oficial do Estado, 2002.

GOVERNO DO ESTADO DO MARANHÃO. Lei n. ${ }^{\circ} 9.413$, de 13 de julho de 2011. Regulamenta o art. 241 da Constituição do Estado do Maranhão, o Capítulo III, Seção VII da Lei Estadual n. ${ }^{\circ}$ 5.405, de 8 de abril de 1992, o Capítulo II, Seção VIII do Decreto Estadual n. ${ }^{\circ} 13.494$, de 12 de novembro de 1993, e institui o Sistema Estadual de Unidades de Conservação da Natureza do Maranhão e dá outras providências. Diário Oficial do Estado, 2011.

GOVERNO DO ESTADO DO MATO GROSSO. Lei n. ${ }^{\circ}$ 9.502, de 14 de janeiro de 2011. Institui o Sistema Estadual de Unidades de Conservação - SEUC, e dá outras providências. Diário Oficial do Estado, Ano CXX, n. ${ }^{\circ}$ 25.497, 2011.

GOVERNO DO ESTADO DO TOCANTIS. Lei n. ${ }^{\circ}$ 1.560, de 5 de abril de 2005. Institui o Sistema Estadual de Unidades de Conservação da Natureza - SEUC, e adota outras providências. Diário Oficial do Estado, n. 1.896, 2005.

HAASE, D.; FRANTZESKAKI, N.; ELMQVIST, T. Ecosystem services in urban landscapes: practical applications and governance implications. Ambio, v. 43, n. 4, p. 407-412, 2014.

HANSMANN, R.; WHITEHEAD, I.; KRAJTER OSTOIĆ, S.; ŽIVOJINOVIĆ, I.; STOJANOVSKA, M.; JONES, N.; BARSTAD, J. Partnerships for urban forestry and green infrastructure delivering services to people and the environment: a review on what they are and aim to achieve. SEEFOR, v. 7, n. 1, p. 9-19, 2016.

HAQ, S.M.A. Urban Green Spaces and an Integrative Approach to Sustainable Environment. Journal of Environmental Protection, v. 2, n. 5, p. 601-608, 2011.

IBGE - INSTITUTO BRASILEIRO DE GEOGRAFIA E ESTATÍ́STICA. Cidades. 2015. Disponível em: <http://cidades.ibge.gov. br/xtras/perfil.php?codmun=355220>. Acesso em: 19 nov. 2016.

JOÃO PESSOA. Lei n. ${ }^{\circ} 12.101$, de 30 de junho de 2011. Institui o Sistema Municipal de Áreas Protegidas de João Pessoa e dá outras providências. Diário Oficial do Município, João Pessoa, 2011.

KABISCH, N.; QURESHI, S.; HAASE, D. Human-environment interactions in urban green spaces: a systematic review of contemporary issues and prospects for future research. Environmental Impact Assessment Review, v. 50, p. 25-34, 2015.

KABISH, N. \& HAASE, D. Green spaces of European cities revisited for 1990-2006. Landscape and Urban Planning, v. 110, p. 113-122, 2013.

KIT CAMPBELL ASSOCIATES. Rethinking open Space: Open Space provision and management: a Way forward. 2001. Disponível em: <http://www.scotland.gov.uk/Resource/Doc/156814/0042172.pdf>. Acesso em: 1. ${ }^{\circ}$ abr. 2015. 
KLEMM, W.; HEUSINKVELD, B.G.; LENZHOLZER, S.; JACOBS, M.H.; VAN HOVE, B. Psychological and physical impact of urban green spaces on outdoor thermal comfort during summertime in The Netherlands. Building and Environment, v. 83, p. $120-128,2015$.

KLIASS, R.G. Parques urbanos de São Paulo. São Paulo: Pini, 1993. 212 p.

LAFORTEZZA, R.; DAVIES, C.; SANESI, G.; KONIJNENDIJK, C. Green infrastructure as a tool to support spatial planning in European urban regions. iForest-Biogeosciences and Forestry, v. 6, n. 3, p. 102-108, 2013.

LEIRIA. Câmara Municipal de Leiria. Departamento de Planejamento e Ordenamento. Programação de equipamentos coletivos para a cidade de Leiria - espaços exteriores urbanos. 26 p. 2012. Disponível em: <https://www. academia.edu/12093142/Programa\%C3\%A7\%C3\%A3o_de_Equipamentos_Coletivos_Para_A_Cidade_de_Leiria_ Espa\%C3\%A7os_Exteriores_Urbanos>. Acesso em: 1. ${ }^{\circ}$ abr. 2015.

LENNON, M. Green infrastructure and planning policy: a critical assessment. Local Environment, v. 20, n. 8, p. 957-980, 2015.

LIIRA, F.; LOHMUS, K.; TUISK, E. Old manor parks as potential habits for Forest flora in agricultural landscapes of Estonia. Biological Conservation, v. 146, n. 1, p. 144-154, 2012.

LIMA, A.M.L.P.; CAVALHEIRO, F.; NUCCI, J.C.; SOUZA, M.A.B.; FIALHO, N.O.; DEL PICCHIA, P.C.D. Problemas de utilização na conceituação de termos como espaços livres, áreas verdes e correlates. In: CONGRESSO BRASILEIRO DE ARBORIZAÇÃO URBANA, 2., São Luís. Anais da SBAU... 1994. p. 539-549.

LIN, B.B.; MEYERS, J.; BEATY, R.M.; BARNETT, G.B. Urban Green Infrastructure Impacts on Climate Regulation Services in Sydney, Australia. Sustainability, v. 8, n. 8, p. 788, 2016.

LIU, W.; CHEN, W.; PENG, C. Assessing the effectiveness of green infrastructures on urban flooding reduction: a community scale study. Ecological Modelling, v. 291, p. 6-14, 2014.

MACEDO, S.S.; CUSTÓDIO, V.; GALENDER, F.C.; QUEIROGA, E.; ROBBA, F. Os sistemas de espaços livres e a construção da esfera pública contemporânea no Brasil: uma rede de pesquisa em âmbito nacional. Paisagem e Ambiente, v. 23, p. 286-297, 2008.

MAES, J.; BARBOSA, A.; BARANZELLI, C.; ZULIAN, G.; SILVA, F.B.; VANDECASTEELE, I.; JACOBS-CRISIONI, C. More green infrastructure is required to maintain ecosystem services under current trends in land-use change in Europe. Landscape Ecology, v. 30, n. 3, p. 517-534, 2015.

MAGNOLI, M. O Parque no Desenho Urbano. Paisagem Ambiente: Ensaios, São Paulo, n. 21, p. 199-214, 2006.

MANEA, G.; MATEI, E.; VIJULIE, J.;TIRLÃ, L.; CUCULICI, R.; COCOS, O.; TISCOVSCHI, A. Arguments for Integrative Management of Protected Areas in the Cities - Case study in Bucharest City. Procedia Environmental Sciences, v. 32, p. 80-96, 2016.

MCPHEARSON, T.; MADDOX, D.; GUNTHER, B.; BRAGDON, D. Local assessment of New York City: biodiversity, green space, and ecosystem services. In: ELMQVIST, T.; FRAGKIAS, M.; GOODNESS, J.; GÜNERALP, B.; MARCOTULLIO, P.J.; MCDONALD, R.I.; PARNELL, S.; SCHEWENIUS, M., SENDSTAD, M.; SETO, K.C.; WILKINSON, C. (Eds.). Urbanization, biodiversity and ecosystem services: challenges and opportunities. [S.I.]: Springer, 2013. p. 313-335.

MELLO, K.; PETRI, L., CARDOSO-LEITE, E.; TOPPA, R.H. Cenários ambientais para o ordenamento territorial de áreas de preservação permanente no município de Sorocaba, SP. Revista Árvore, Viçosa, v. 38, n. 2, p. 309-317, 2014.

MELLO, K.; TOPPA, R.H.; CARDOSO-LEITE, E. Priority areas for forest conservation in an urban landscape at the transition between Atlantic forest and cerrado. CERNE, v. 22, p. 277-288, 2016.

MOTA, M.T.; CARDOSO-LEITE, E.; SOLA, F. "Parques" em paisagem urbana e seu potencial para implantação de áreas protegidas - estudo de caso no sudeste do Brasil. REVSBAU, Piracicaba, v. 9, n. 1, p. 59-77, 2014. 
NEWELL, J.P.; SEYMOUR, M.; YEE, T.; RENTERIA, J.; LONGCORE, T.; WOLCH, J.R.; SHISHKOVSKY, A. Green Alley Programs: Planning for a sustainable urban infrastructure? Cities, v. 31, p. 144-155, 2013.

OLIVEIRA, F.L. Modelos Urbanísticos Modernos e Parques Urbanos: as relações entre urbanismo e paisagismo em São Paulo na primeira metade do século XX. 82p. Dissertação (Doutorado) - Universidade Politécnica de Catalunha, Barcelona, Espanha, 2008.

PAUCHARD, A. \& BARBOSA, O. Regional assessment of Latin America: rapid development and social economic inequity threaten biodiversity hotspots. In: ELMQVIST, T.; FRAGKIAS, M.; GOODNESS, J.; GÜNERALP, B.; MARCOTULLIO, P.J.; MCDONALD, R.I.; PARNELL, S.; SCHEWENIUS, M., SENDSTAD, M.; SETO, K.C.; WILKINSON, C. (Eds.). Urbanization, biodiversity and ecosystem services: challenges and opportunities. Springer, 2013. p. 589-608.

PORTO ALEGRE. Lei Complementar n. ${ }^{\circ}$ 679, de 26 de agosto de 2011. Institui o Sistema Municipal de Unidades de Conservação da Natureza de Porto Alegre (SMUC - POA) e dá outras providências. Diário Oficial do Município, 2011.

SANCHO, A. \& DE DEUS, J.A.S. Áreas protegidas e ambientes urbanos: novos significados e transformações associados ao fenômeno da urbanização extensiva. Sociedade \& Natureza, v. 27, n. 2, 2015.

SCHEWENIUS, M.; MCPHEARSON, T.; ELMQVIST, T. Opportunities for Increasing Resilience and Sustainability of Urban SocialEcological Systems: Insights from the URBES and the Cities and Biodiversity Outlook Projects. Ambio, v. 43, n. 4, p. 434-444, 2014. Disponível em: <http://link.springer.com/article/10.1007\%2Fs13280-014-0505-z>. Acesso em: 16 jan. 2017.

SEGAWA, H. Arquitetura Paisagística até 1930. In: FARAH, I.; SCHELEE, M.B.; TARDIN, R. (Orgs.). Arquitetura paisagística contemporânea no Brasil. São Paulo: Ed. SENAC, 2010. 227p.

SMANIOTTO COSTA, C.; SUKLJE ERJAVEC, I.; MATHEY, J. Green spaces - a key resources for urban sustainability. The GreenKeys approach for developing green spaces. Urbani Izziv, v. 19, n. 2, p. 199-211, 2008.

SOROCABA. Lei Municipal $n^{\circ}$. 11.022, 16, de dezembro de 2014. Lei Ordinária. Ementa: Revisão da Lei n. 7.122 de 04/6/2004, Dispõe sobre a revisão do Plano Diretor de Desenvolvimento Físico Territorial do município de Sorocaba e dá outras providências. Semanário Oficial, ano 24, n. ${ }^{\circ}$ 1.666, 2014.

SOROCABA. Lei n. ${ }^{\circ} 11.073$, de 31 de março de 2015. Institui o Sistema Municipal de Áreas Protegidas, Parques e Espaços Livres de Uso Público e dá outras providências. Diário Oficial do Município, 2015.

SOUZA, P.C.A. Funções Sociais e Ambientais de Parque Urbano Instituído como Unidade de Conservação: percepção dos usuários do Parque Natural Municipal Barigui em Curitiba, Paraná. 146p. Dissertação (Mestrado) - Programa de Pós-graduação em Gestão Urbana Do Centro de Ciências Exatas e de Tecnologia, Pontifícia Universidade Católica do Paraná, Curitiba, 2010.

SWAFFIELD, S. Empowering landscape ecology - connecting science to governance through design values. Landscape Ecology, v. 28, p. 1193-1201, 2013.

WANG, Y.; BAKKER, F.; DE GROOT, R.; WÖRTCHE, H. Effect of ecosystem services provided by urban green infrastructure on indoor environment: a literature review. Building and Environment, v. 77, p. 88-100, 2014.

WOLCH, J.R.; BYRNE, J.; NEWELL, J.P. Urban green space, public health, and environmental justice: the challenge of making cities "just green enough". Landscape and Urban Planning, v. 125, p. 234-244, 2014.

WU, J. Urban ecology and sustainability: the state-of-the-science and future directions. Landscape and Urban Planning, v. 125, p. 209-221, 2014.

XIANG, W.N. Working with wicked problems in socio-ecological systems: awareness, acceptance, and adaptation. Landscape and Urban Planning, v. 110, p. 1-4, 2013. 